Research letter

\title{
Preoperative planning software in vertebrology: issues and outlook
}

\author{
Alexander S. Fedonnikov ${ }^{1}$, Anatoly L. Kovtun ${ }^{2}$, Leonid Y. Kossovich ${ }^{3}$, Irina V. Kirillova ${ }^{3}$, Anna S. Kolesnikova ${ }^{3}$, \\ Igor A. Norkin ${ }^{1}$
}

${ }^{1}$ Saratov State Medical University n.a. V.I. Razumovsky, Saratov, Russia

${ }^{2}$ Foundation of Advanced Studies, Moscow, Russia

${ }^{3}$ Saratov State University, Saratov, Russia

Received 28 April 2017, Revised 31 May 2017, Accepted 19 June 2017

(c) 2017, Fedonnikov A.S., Kovtun A.L., Kossovich L.Y., Kirillova I.V., Kolesnikova A.S., Norkin I.A.

(C) 2017, Russian Open Medical Journal

Abstract: It is established that relevance of the use of computer systems of the preoperative planning in activities of scientific and medical staff was confirmed $62.3 \%$ of the respondents. According to the survey $34.4 \%$ of respondents do not use any computer planning systems, and $21.3 \%$ of respondents could not name any specific system they are using. Problem of the lack of systematic training of specialized professionals working with specialized software products was revealed $-62.3 \%$ of respondents obtain the information about the specialized software products only in the frames of various kinds of conferences and workshops.

Keywords: preoperative planning software, vertebrology, sociological research

Cite as Fedonnikov AS, Kovtun AL, Kossovich LY, Kirillova IV, Kolesnikova AS, Norkin IA. Preoperative planning software in vertebrology: issues and outlook. Russian Open Medical Journal 2017; 6: e0408.

Correspondence to Alexander S. Fedonnikov. Address: Scientific and Research Institute of Traumatology, Orthopedics and Neurosurgery, Saratov State Medical University n.a. V.I. Razumovsky, 148, Chernyshevskogo str., Saratov, 410002, Russia. Phone: +7-905-3682997. E-mail: fedonnikov@mail.ru.

\section{Introduction}

The treatment of complicated anatomic damages caused by trauma or conjenital deformities is always a challenge for surgeons. Addressing this problem medical information systems (MIS) are currently being used. These systems are designed to automate the management of medical and diagnostic activity of standard health care organisations providing outpatient, inpatient, and other types of health care [1, 2]. According to the developed classification of one of the world's leading research and consulting companies in the field of information technology Gartner Inc. (USA), there are 5 generations of MIS developement (Collector, Archivist, Helper, Colleague and Mentor) [3]. The first generation (Collector) includes disparate systems keeping medical records and capable of collecting the consolidated financial statements without the required level of detail of electronic medical records. The second generation (Documentor) is a more advanced system keeping medical records in the networking of health care institutions, but without the ability to support evidence-based medicine and the accumulation of knowledge. The third generation (Helper) is a patient-centric system of conducting electronic medical records with elements supporting evidence-based medicine and the accumulation of knowledge.The fourth generation (Colleague) includes the third generation capabilities, plus the ability to support decision-making. The developers are beginning to implement the principles of evidencebased medicine. The fifth generation (Mentor) includes the fourth generation capabilities with the addition of functional possibilities in applications to prompt physicians to possible ways of treatment and diagnosis of patients. According to the forecast of Gartner Inc. MIS of the 4th generation should have been implemented and MIS of the 5th generation should have appeared by 2016. In Russia among the most popular preoperative planning systems, which by its functionality are beyond the scope of the requirements imposed on the MIS 1st, 2nd and 3rd generation are: TraumaCAD [4-7], MediCAD (http://www.hectec.de/content/index.php/us), OrthoView [810], Sectra AB (http://www.sectra.com/medical/osteoporosis/index.html), Surgimap $[11,12]$ IMPAX orthopedic instruments (http://www.agfahealthcare.com). The aim of this study is the identification of the key challenges arising during the implementation of the preoperative planning systems in the practice of spine surgeons.

\section{Material and Methods \\ Design}

A sociological research was conducted in the form of full-time survey of 61 spine surgeons practicing in Russia, accounting for about $21 \%$ of the total number of such specialists in Russia (according to the official data of the Interregional Association of Spine Surgeons 2016). The VII Congress of the Association of Spine Surgeons (Moscow, May 27, 2016) and Saratov Scientific Research Institute of Traumatology and Orthopedics (Saratov, June 20, 2016) are the venues of the sociological survey. 
Table 1. Distribution of respondents on the basis of qualifying category and scientific degree, no. (\%)

\begin{tabular}{|c|c|c|c|c|c|c|}
\hline \multicolumn{4}{|c|}{ Qualification category } & \multicolumn{3}{|c|}{ Scientific degree } \\
\hline Second & First & Higher & None & $\mathrm{PhD}$ & DSc & None \\
\hline $8(13.1)$ & $14(23.0)$ & $15(24.6)$ & $24(39.3)$ & $15(24.6)$ & $11(18.0)$ & $35(57.4)$ \\
\hline
\end{tabular}

PhD, Doctorate of Philosophy; DSc, Doctorate of Sciences.

Table 2. Distribution of experts on the basis of general medical training and work experience in spine surgery, no. (\%)

\begin{tabular}{|c|c|c|c|c|c|}
\hline Period & up to 5 years & $5-10$ years & $10-20$ years & More than 20 years & Not specified \\
\hline General experience & $21(34.4)$ & $16(26.2)$ & $11(18.0)$ & $10(16.4)$ & $3(5.4)$ \\
\hline Experience in spine surgery & $24(39.3)$ & $19(31.1)$ & $9(14.8)$ & $5(8.2)$ & $4(6.6)$ \\
\hline
\end{tabular}

Table 3. Distribution of experts on the basis of awareness and use medical preoperative planning software in practice, no. (\%)

\begin{tabular}{|c|c|c|c|c|c|}
\hline & \multicolumn{5}{|c|}{ Preoperative planning systems } \\
\hline & Orthoview & MediCAD 3D & Traumacad & IMPAX OrthopaedicTools & Surgimap \\
\hline Known & $23(37.7)$ & $28(45.9)$ & $17(27.9)$ & $11(18.0)$ & $17(27.9)$ \\
\hline Used & $7(11.5)$ & $8(13.1)$ & $5(8.2)$ & $4(6.6)$ & $4(6.6)$ \\
\hline
\end{tabular}

Table 4. Ranking of disadvantages, risks in the use of existing PPS and requirements to specialized software products

\begin{tabular}{|c|c|c|c|}
\hline Disadvantages & Risks & Requirements & Ranking \\
\hline $\begin{array}{l}\text { The absence of the Russian-language } \\
\text { version and the technical documentation }\end{array}$ & Providing in accurate information doctor & $\begin{array}{l}\text { The presence of the Russian-language } \\
\text { version and the technical documentation }\end{array}$ & 1 \\
\hline Absence/irrelevant data base implant & Incorrect selection of the implant & $\begin{array}{l}\text { Automated recommendations for operation } \\
\text { planning }\end{array}$ & 2 \\
\hline Uncomfortable/complex user interface & Technical failure & The presence of the mobile version & 3 \\
\hline The complexity of the work instruction & $\begin{array}{l}\text { Insufficient protection of the patient's personal } \\
\text { data }\end{array}$ & The possibility of designing implants & 4 \\
\hline
\end{tabular}

\section{Subjects}

The group of specialists surveyed had a high level of professional and academic qualifications. The majority of respondents (60.7\%) have the qualification category of health worker; while experts with the highest category (40.5\%) are dominating. $42.6 \%$ of the experts have $\mathrm{PhD}$ or Doctor of Science (Table 1).

The qualification level in the context of professional experience of experts is underpinned by the length of work experience of the experts: $60.6 \%$ of respondents have more than 5 years of total work experience, and $34.4 \%$ of the respondents have more than 10 years of total work experience. At the same time $54.1 \%$ of the respondents have more than 5 years of experience particularly in the field of spine surgery and $23.0 \%$ of respondents have more than 10 years of experience (Table 2).

\section{Questionnaire}

A specially designed questionnaire consisted of two thematic parts, dedicated to the problem of medical preoperative planning software (PPS) use while planning surgical intervention on the spinal pelvic complex. The full text of the questionnaire is presented in Appendix 1. The first part included the questions relating to the professional level and employment of experts (work experience, position, qualifications). The second part contained questions related to the relevance of development and use of 5 most famous PPS in Russia to ensure effective surgical correction of pathology of spinal-pelvic complex.

\section{Results}

The relevance of establishment, implementation in practice and training of specialists to work with the PPS providing the effective surgical treatment of pathologies spinal-pelvic complex is revealed in the results of the analysis of responses of the respondents to the questions of the second block.

In general, $62.3 \%$ of respondents believe that the use of a computer programme PPS in the activities of scientific and medical staff is necessary.In terms of opinion of medical specialists (traumatologists, orthopedists, neurosurgeons), the proportion of professionals who support this thesis makes up $70.3 \%$. However, the revealed theoretical understanding of the relevance is not supported by actual practice. According to the survey, $34.4 \%$ of professionals do not use any computer PPS, and yet $21.3 \%$ can not name exactly what they use. This actualizes both the development of these computer systems and training. The necessity of creation and implementation of PPS is confirmed by the fact that $68.9 \%$ of the surveyed experts participate in the planning and conducting of operations.

The interpretation of the survey results concerning awareness and use of PPS in practice gives extra confirmation to our conclusion about the existing gap between the theoretical knowledge and practice.This conclusion is confirmed by the fact that in average approximetely half of the specialists know about the existence of above-mentioned software systems, but in fact, these systems are used by very few ones (Table 3 ).

Today there is a problem of absence of systematic training of dedicated experts working with specialized software products. According to our data, different kinds of conferences and workshops (62.3\%), communication with colleagues $(39.3 \%)$, 
acquaintance with scientific publications (37.7\%) and obtaining information from the developers $(21.3 \%)$ are the main sources of information about the use of PPS in spine surgery (Figure 1). Neither of experts surveyed pointed out specialized training courses (modules) as a source of information. This indicates the absence of a priority interest of the main subjects of the turnover of specialized software (developers, distributors, educational and medical institutions, healthcare providers) in the increase of the level of dedicated experts' professional competence.

A number of survey questions concerned the disadvantages and risks of known PPS, and the requirements imposed by users to such software products.The ranking analysis of processing of results of the respondents' answers is presented in Table 4.

\section{Discussion}

The analysis of the presented data allows us to formulate the key problems and possible solutions in the development and implementation of vertebrology PPS in the Russian practice:

i) Insufficiency of clinical use of these software systems even in case of awareness of its utulity. On average, no more than $10 \%$ of the respondents use PPS in their work despite the fact that $44.7 \%$ of the experts know about them. Thus, the development and implementation of PPS for ensuring surgical treatment of pathology of spinal-pelvic complex is believed to be actual by high-qualified specialists (according to the results of our study this opinion is shared by $62.3 \%$ of respondents).

ii) Absence of systematic training of profile experts working with specialized software products. Different kinds of conferences and workshops (62.3\%), communication with colleagues (39.3\%), acquaintance with scientific publications $(37.7 \%)$ and obtaining information from the developers $(21.3 \%)$ are the main sources of information about the use of PPS in spine surgery according to our data. Neither of experts surveyed pointed out specialized training courses (modules) as a source of information. This indicates the absence of a priority interest of the main subjects of the turnover of specialized software (developers, distributors, educational and medical institutions, healthcare providers) in the increase of professional competence level of concerned experts. In this regard, specialized training centers based on specialized universities and research institutes should be established. Both public and private partnership is appropriate to be considered as one of the financial and legal mechanisms. The state, on the one hand, in this mechanism, conveys the right to use a particular object of the state property, and a private organization (the developer), on the other hand, provides as a transfer of innovative practices for medical professionals, and improvement of software products in collaboration with scientists and practitioners.

Nowadays in the relevant domestic and foreign scientific editions there are no sociological reserachs dealing with PPS use in spine surgery. The relevance of the sociological study is caused by the extreme rarity of clinical application of SPP in our country, which is confirmed by single domestic publications [13, 14], while there is a significant number of similar foreign publications, indicating the use of such systems in the US, UK and Germany [4$12,15-20]$

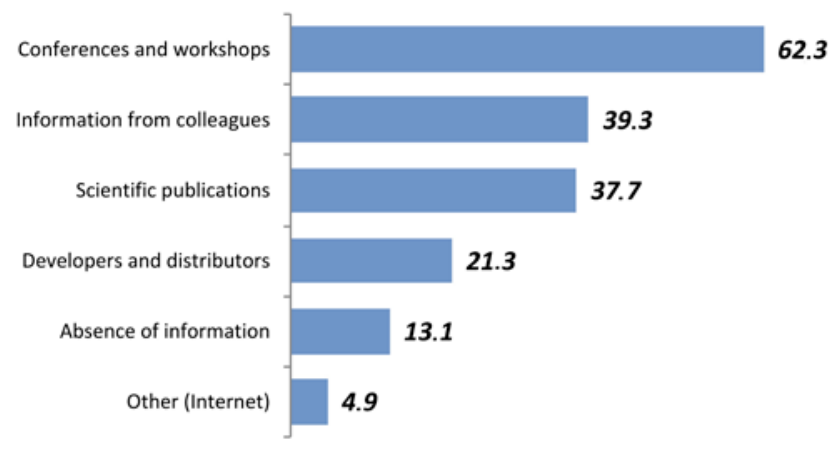

Figure 1. Sources of information about specialized PPS (values are presented in percents from number of respondents)

\section{Conclusion}

The provided sociological research revealed the main difficulties of the implementation of SPP in surgical practice. Lack of software products focused on Russia and inappropriate database of implants are the main risk factors of incorrect preoperative planning.

\section{Conflict of interest}

Autors have no conflict of interest.

\section{References}

1. Shortliffe EH, Perreault LE Medical Informatics. New York: Springer Science, 2001: $856 \mathrm{p}$.

2. Guidelines for using medical information systems of medical institutions (MIS MI). http://www.garant.ru/products/ipo/prime/doc/71238346/\#ixzz4MHd gNvAx. Access: 13.02.2017

3. Handler TJ, Hieb BR. The Gartner 2007 Criteria for the Enterprise CPR. Industry Research 2007; G00149693: 1-7. https://www.gartner.com/doc/414778/gartner--criteria-enterprise-cpr.

4. Steinberg EL, Shasha N, Menahem A, Dekel S. Preoperative planning of total hip replacement using the TraumaCad ${ }^{\text {TM }}$ system. Arch Orthop Trauma Surg 2010; 130: 1429-1432. https://doi.org/10.1007/s00402010-1046-y.

5. Steinberg EL, Segev E, Drexler M, Tov TB, Nimrod S. Preoperative planning of orthopedic procedures using digitalized software systems. Isr Med Assoc J 2016; 18: 354-358. https://www.ncbi.nlm.nih.gov/pubmed/27468530.

6. Westacott DJ, McArthur J, King RJ, Foguet P. Assessment of cup orientation in hip resurfacing: a comparison of TraumaCad and computed tomography. J Orthop Surg Res 2013; 8: 8. https://doi.org/10.1186/1749-799X-8-8.

7. Bitar Y FE, Jackson TJ, Lindner D, Botser IB, Stake CE, Domb BG. Predictive value of robotic-assisted total hip arthroplasty. Orthopedics 2015; 38: e31e37. https://dx.doi.org/10.3928/01477447-20150105-57.

8. Hsu AR, Kim JD, Bhatia S, Levine BR. Effect of training level on accuracy of digital templating in primary total hip and knee arthroplasty. Orthopedics 2012; 35: e179-e183. https://dx.doi.org/10.3928/01477447-20120123-15.

9. Rhee $\mathrm{SJ}$, Seo $\mathrm{CH}$, Suh JT. Navigation-assisted total knee arthroplasty for patients with extra-articular deformity. Knee Surg Relat Res 2013; 25(4): 194-201. https://dx.doi.org/10.5792/ksrr.2013.25.4.194.

10. Hosseinzadeh P, Ross DR, Walker JL, Talwalkar VR, Iwinski HJ, Milbrandt TA. Three methods of guided growth for pediatric lower extremity angular deformity correction. lowa Orthop J 2016; 36: 123127. https://www.ncbi.nlm.nih.gov/pubmed/27528848. 
11. Akbar M, Terran J, Ames CP, Lafage V, Schwab F. Use of Surgimap Spine in sagittal plane analysis, osteotomy planning, and correction calculation. Neurosurg Clin N Am 2013; 24 (2): 163-72. https://doi.org/10.1016/i.nec.2012.12.007.

12. Helmy NA., El-Sayyad MM, Kattabei OM. Intra-rater and inter-rater reliability of Surgimap Spine software for measuring spinal postural angles from digital photographs. Bull Fac Phys Ther 2015; 20(2): 193199. https://dx.doi.org/10.4103/1110-6611.174719.

13. Khominets VV, Kudyashev AL, Shapovalov VM, Miroevsky FV. Modern approaches to diagnostics of combined degenerative hip and spine pathology. Travmatologiya i Ortopediya Rossii 2014; (4): 16-26. Russian. http://dx.doi.org/10.21823/2311-2905-2014-0-4-16-26.

14. Kudyashev AL, Shapovalov VM, Averkiev VA, Nadulich KA, Teremshonok AV, Rezvantsev MV, et al. Radiographic evaluation of sagittal spinopelvic relations in patients with arthrosis deformans of the hip. Geniy Ortopedii 2013; (3): 27-32. Russian. https://elibrary.ru/item.asp?id=21014546.

15. Mittag F, Ipach I, Schaefer R, Meisner C, Leichtle U. Predictive value of preoperative digital templating in THA depends on the surgical experience of the performing physician. Orthopedics 2012, 35(2): e144-e147. https://dx.doi.org/10.3928/014774447-20120123-14.

16. Davila JA, Kransdorf MJ, Duffy GP. Surgical planning of total hip arthroplasty: accuracy of computer-assisted EndoMap software in predicting component size. Skeletal Radiol 2006; 35: 390-393. https://dx.doi.org/10.1007/s00256-006-0106-4.

17. Powers CC, Ho H, Beykirch SE, Huynh C, Hopper RH, Engh CA, Engh CA. A comparison of a secondand a third-generation modular cup design. $J$ Arthroplasty 2010, 25: 514-520. https://dx.doi.org/10.1016/j.arth.2009.02.018.

18. Callary SA, Field JR, Campbell DG. Low wear of a second-generation highly crosslinked polyethylene liner: a 5-year radiostereometric analysis study. Clin Orthop Relat Res 2013; 471: 3596-3600. https://dx.doi.org/10.1007/s11999-013-3188-z.

19. Barrack RL, Krempec JA, Clohisy JC, McDonald DJ, Ricci WM, Ruh EL, Nunley RM. Accuracy of acetabular component position in hip arthroplasty. J Bone Joint Surg Am 2013; 95: 1760-1768. https://dx.doi.org/10.2106/JBJS.L.01704.

20. Langlois J, Zaoui A, Scemama C, Martell J, Bragdon C, Hamadouche M. Validation of a computer-assisted method for measurement of radiographic wear in total hip arthroplasty using all polyethylene cemented acetabular components. J Orthop Res 2015; 33(3): 417-420. https://dx.doi.org/10.1002/jor.22777.

\section{Authors:}

Alexander S. Fedonnikov - MD, PhD, Deputy Director for Science and Innovations, Scientific and Research Institute of Traumatology, Orthopedics and Neurosurgery, Saratov State Medical University n.a. V.I. Razumovsky, Saratov, Russia. http://orcid.org/0000-0003-0344-4419.

Anatoly L. Kovtun - DSc, Professor, Head of the Project Group, Direction of Chemical-Biological and Medical Research, Foundation of Advanced Studies, Moscow, Russia. http://orcid.org/0000-0003-4248-6216.

Leonid Y. Kossovich - DSc, Professor, President, Saratov State University, Saratov, Russia. http://orcid.org/0000-0002-4775-7348.

Irina V. Kirillova - PhD, Associate Professor, Director, Education and Research Institute of Nanostructures and Biosystems, Saratov State University, Saratov, Russia. http://orcid.org/0000-0001-8053-3680.

Anna S. Kolesnikova - PhD, Associate Professor, Department of Mathematical Theory of Elasticity and Biomechanics, Saratov State University, Saratov, Russia. http://orcid.org/0000-0003-2033-1192.

Igor A. Norkin - MD, DSc, Professor, Director of Saratov Scientific and Research Institute of Traumatology and Orthopedics, Saratov, Russia. http://orcid.org/0000-0002-6770-3398. 


\section{DEAR PARTICIPANTS OF THE VII CONGRESS OF THE ASSOCIATION OF SPINE SURGEONS!}

Saratov State University in cooperation with the Interregional Association of Spine Surgeons of

Russia and Saratov Scientific and Research Institute of Traumatology and Orthopedics is conducting a survey to identify the key issues of preoperative planning software use.

\section{We kindly ask you to participate in this study.}

Your opinion is very important to us.

\section{SPECIAL SECTION}

1. How do you think is it important to use preoperative planning software in your daily work?

1.1. Without a doubt, it is.

1.2. Its efficiency is low in their modem form.

1.3. No it is not

1.4. Difficult to answer

2. Do you use any specialized medical software?

2.1. No

2.2. Yes (specify which exactly)

2.3. Yes, but it's difficult to identify

3. How do you mostly get information about specialized medical software packages?

3.1 I do not get this information.

3.2 I get it from scientific publications.

3.3 I get at conferences and workshops.

3.4 I get it from colleagues.

3.5 I get it from managers or developers of such preoperative planning software.

3.6. Other (specify)

4. Do you participate in the planning and conducting of surgical operations?

4.1 I don't take part neither in the planning nor in the conducting of surgical operations.

4.2 I participate only in the planning of surgical operation.

4.3 I participate only in the conducting of surgical operation.

4.4 I participate both in the planning and conducting of surgical operation.

5. Please indicate what kind of preoperative planning software listed below do you know about and what kind of it do you use:

\begin{tabular}{|l|l|l|}
\hline \multicolumn{1}{|c|}{ Preoperative planning software } & I know & I use \\
\hline Orthoview & & \\
\hline MediCAD 3D & & \\
\hline Traumacad & & \\
\hline IMPAX Orthopaedic Tools & & \\
\hline Surgimap & & \\
\hline Other (specify) & & \\
\hline
\end{tabular}

6. What kind of functions of preoperative planning software do you use mostly?

6.1. Creating a 3D image of interested object.

6.2. Automatic selection of the implant.

6.3. Uploading of planning result to the medical information system.

6.4. Multimode view of patient studies.

6.5. Other (specify) 
DRAW IN CIRCLE THE SELECTED NUMBERS OR WRITE DOWN YOUR ANSWERS WHILE WORKING WITH QUESTIONNAIRE E-MAIL NANO-BIO@SGU.RU

7. Please identify the most significant disadvantages of famous preoperative planning software?

7.1. The absence of Russian-language version.

7.2. Inconvenient / complicated user interface.

7.3. Late update / absence of implants database.

7.4. The absence of user Russian-language costumer documentation.

7.5. The complexity of operating instruction.

7.6. Other (specify)

8. What dangers have you personally or someone from your colleagues faced working with preoperative planning software?

8.1. Providing of false information (recommendations) to the doctor or to the patient.

8.2. Incorrect selection of the implant (mismatching of size/type).

8.3. Incorrectly received data about the patient due to technical failure.

8.4. Absence/lack of personal data of the patient protection.

8.5. Other (specify)

9. What are the main advantages according to your opinion should have preoperative planning software?

9.1. Mobile version availability.

9.2. The Russian-language interface.

9.3. Automatic recommendations for the planning.

9.4. Option of modification/development of implants.

9.5. Other (specify)

\section{COMMON SECTION}

10. Total medical experience:
10.1. Up to 5 years
10.2. 5-10 years
10.3. $10-20$ years
10.4. More than 20 years

11. Work experience in spine surgery:
11.1.Up to 5 years
11.2.5-10 years
11.3.10-20 years
11.4. More than 20 years

12. Your company (write)

13. Your position (write)

14. Do you have a qualification category?
14.1. II category
14.2. I category
14.3. Higher category
14.4.. Absent

15. Do you have an academic degree?
15.1. $\mathrm{PhD}$
15.2. Doctor of Science
15.3. .Absent

16. Your remarks

Thank you for your time!

DRAW IN CIRCLE THE SELECTED NUMBERS OR WRITE DOWN YOUR ANSWERS WHILE WORKING WITH QUESTIONNAIRE E-MAIL NANO-BIO@SGU.RU 